\title{
Current Account Dynamics, Adjustment and Capital Mobility in Bangladesh
}

\author{
Mohammad Masud Alam', Rezai Karim Khondker², Mohammad Shahansha Molla ${ }^{3}$ \\ ${ }^{1}$ Assistant Professor of Economics, Shahjalal University of Science \& Technology, Sylhet, Bangladesh \\ ${ }^{2}$ Professor, Dhaka School of Economics, Dhaka, Bangladesh \\ ${ }^{3}$ Assistant Professor of Finance, Leading University, Sylhet, Bangladesh
}

\begin{abstract}
This paper examines current account (CA) dynamics, its relationship with the degree of capital mobility and the state of integration of the Bangladesh capital market with the global capital market. For the period 1976-2012, findings of AR (1) process shows a rigid CA position along with its slow adjustment and its inflexibility against real shocks, lower degree of capital mobility and a slow progress of capital market integration with the rest of the world. Compared to the period of fixed exchange rate regime, lesser degree of rigidity has been observed during the flexible exchange rate period suggesting a smooth and flexible current account position; but shows an increased degree of rigidity and capital immobility for the overall time period under consideration. These findings reveal some important policy implications in respects of current and capital account liberalization, deregulation of domestic markets and removing entry barriers on the part of Bangladesh to boost up FDI and remittance inflows.
\end{abstract}

Key words: current account dynamics, capital mobility, Bangladesh

JEL Classification Code: F32; E22

\section{INTRODUCTION}

The scenario of persistent inflation, slow improvement of balance of payments (BoP) condition and a moderate but steady growth rate of GDP while an ongoing global slowdown, has been the focus of a lively debate among policymakers and economists in Bangladesh. Much of the debate has concentrated on the large current account (CA) surplus along with sustained sizable trade deficits and an incessantly increasing trend in remittance inflows during the last three decades. One of the leading issues confronting policy makers in Bangladesh is the pattern of CA dynamics and the adjustment process i.e., whether CA would be back towards its equilibrium or the 'steady-state' value following an adverse shock or not. There are wide-ranging views on Bangladesh's CA position of a surplus in excess of $1.77 \%$ of GDP (WDI, 2012). The question of CA dynamics and post-shock adjustment is certainly an important issue for Bangladesh which is increasingly in the focus of global investors. For, a CA surplus (deficit) of an economy may indeed be a superb (disturbing) sign for the future economic growth; or whether there would be any possibility to undergo severe external shocks (Lane \& Milesi-Ferretti 2004, 
Freund 2000). In fact, some literatures present evidences (Mann, 1999, Freund, 2000 \& Chinn and Prasad, 2003) concerning the threshold level of CA deficit as a fraction of GDP and the timing of adjustment, which show that on average CA tended to adjust when it approached levels around $4-5 \%$ of domestic GDP.

Seen from this perspective, first objective of this paper is to deal with the issue of dynamics of the Bangladesh's CA position. Secondly, applying the Autoregressive (AR 1) process this paper will examine the adjustment speed of CA that can tell us a great deal about capital mobility (Bulut 2013, Taylor 2002). The previous studies focus mainly on the CA sustainability, CA dynamics and capital mobility in developed countries especially in the U.S. and for the EU countries. Considering the recognized information of huge differences between Bangladesh and most developed countries, not only on policy making institutions but also on planner's views in various macroeconomic and trade problems, it is worthwhile and necessary to study the CA dynamics and capital mobility in this country. However, there has been no literature published to date that has examined this issue on Bangladesh. This gap of previous literature must be filled. The main purpose of the analysis of CA is to inform the government about the global competitive position of the nation, both future and current economic trends and to help in formulating country's monetary, fiscal and trade policies in a more prudent way. Some policymakers and economists argue that the balance of payments no longer matters as a noteworthy policy on globalization and, because globally integrated capital markets along with financial liberalization can assist a country to diminish their trade and current account deficits (Feldstein \& Horioka 1980). Trade openness, international capital mobility and easier access to global financial markets has allowed open economies to increase their domestic investment further than what could be financed by a country's own savings and reducing the cost of current account adjustments (Clower \& Ito 2012, Faruqee \& Lee 2009). Considering country's monetary and trade policy, how smooth the adjustment speed of current account balances (CABs) in Bangladesh would be and how the global capital mobility and financial flows can play a significant role in the adjustment process? This paper examines these questions by using AR (1) process of current account dynamics and the associated degree of capital mobility in Bangladesh over the past four decades. The remainder of this paper is as follows. Section II provides a theoretical framework on the model of AR (1) process of current account dynamics. This section also outlines how an econometric parameter can depict dynamics, adjustment process and can explain real shocks of an open economy resulting from a variety of sources. In Section III we present our data and conduct stationary tests employing conventional unit root and Dickey-Fuller test. Section IV builds on the analysis of results to examine the current account dynamics and degree of capital mobility. We present concluding remarks in section $\mathrm{V}$ along with some policy recommendations.

\section{Methodology}

\section{Econometric framework}

A number of approaches have been employed to investigate the CA dynamics and the adjustment process of $\mathrm{CAB}$ and its relationship to gauge the degree of capital mobility. While the AR (1) approach to the current account is a standard and parsimonious framework (Obstfeld \& Taylor, 2005) for analysis of dynamics and capital mobility, it is not particularly well corroborated by others (Bulut 2012, Raybaudi et. al. 2004, Calderon et al , 2002) for assessing current account dynamics. The AR (1) is the simplest but significant 
linear time-series process which captures dynamics. It indicates the notion that what we know about the future depends on realizations from today, yesterday, and so on (Hamilton 1994). In this section we model the dynamics of CA/Y that can give us inkling about capital mobility. Using simple AR (1) process we can also investigate the adjustment speed of CA/Y to check whether it will eventually move back towards its equilibrium or 'steady-state' value after an adverse shock (Bulut 2013, Taylor 2002).

Following Brockwell, Peter and Davis (1987), Hamilton (1994) and Gunnip (2006), let time be indexed with $\mathrm{t}$ and let $\mathrm{t} \in\{-\infty \ldots-1,0,1,2 \ldots \infty\}$. Let $\varepsilon_{t} \sim \mathrm{N}(0,1)$ be an identically and independently distributed (or i.i.d. shock). This means that, no matter what the date is, the distribution of $\varepsilon_{t}$ follows the standard normal distribution. The random variable $\mathrm{X}_{\mathrm{t}}$ follows an $\mathrm{AR}(1)$ if we can write it as

$$
X_{t}=(1-\rho) \phi+\rho X_{t-1}+\psi \varepsilon_{t}
$$

If we consider the stationary assumption of $-1<\rho<1$ and let time $t \rightarrow \infty$ then

$$
X_{t}=\phi+\psi \sum_{j=0}^{\infty} \rho^{j} \varepsilon_{t-j}
$$

where $\rho, \phi$ and $\psi$ are fixed scalars, or the parameters of the process. Equation (2) is the infiniteorder moving average. Using equation (2), the AR (1) variable, $X_{t}$ can be presented as an infinite sum of past shocks, where more distant shocks get smaller and smaller weights. It is because the coefficients in equation (2) are geometrically declining since $|\rho|<1$.

The dynamics of the AR (1) are summarized by its 'autocorrelation parameter $\rho$. It is a measure of the linear dependence of today's value $X_{t}$ on previous time value $X_{t-1}$. It is defined as:

$$
\operatorname{Corr}\left(X_{t}, X_{t-1}\right)=\operatorname{Cov}\left(X_{t}, X_{t-1}\right) / \operatorname{Var}\left(X_{t}\right)
$$

where,

$$
\begin{aligned}
& \operatorname{Cov}\left(X_{t}, X_{t-1}\right)=\operatorname{Cov}\left(\phi(1-\rho)+\rho X_{t-1}+\psi \varepsilon_{t}, X_{t-1}\right. \\
& =\rho \operatorname{Cov}\left(X_{t-1}, X_{t-1}\right) \\
& =\rho \operatorname{Var}\left(X_{t-1}\right)
\end{aligned}
$$

Since these are unconditional moments of a stationary time series process, we must have that

$$
\operatorname{Var}\left(X_{t-1}\right)=\operatorname{Var}\left(X_{t}\right)
$$

Therefore,

$$
\operatorname{Corr}\left(X_{t}\right)=\rho
$$

If $\rho=0$ then there are no dynamics and showing $X_{t}$ is i.i.d., follow normal distribution. If $\rho \mid<1$ then the process is said to be stationary and the distant past is matters. If $\rho=1$ then the process is called a "unit-root process" and its memory is infinite. If $|\rho|>1$ then the process is 'explosive.' Thus, for $|\rho|<1$, the system is considered stable, or the further 
back in time a given change occurs, the less it will affect the present. The given change eventually dies down over time. For $|\rho|>1$, the system blows up. A given change in the past time period increasingly affects the future as time goes on. Under this framework, to investigate the current account dynamics and its relationship with capital mobility we used simple AR (1) regression of the following form:

$$
\Delta(C A / G D P)_{t}=\alpha+\beta(C A / G D P)_{t-1}+U_{t}
$$

Where, $\mathrm{CA}=$ current account

$\mathrm{GDP}=$ Country's gross domestic product

$\mathrm{t}=$ Time period

$\mathrm{U}=$ Random error term

$\Delta=$ First difference operator

The main task is to examine the convergence speed $\beta$ and error variance $\sigma^{2}$. How should we interpret the model parameters? If $\beta$ is small (close to zero) we would infer that the country has a flexible current account and the capacity to run persistent deficits. Conversely, if $\beta$ is high (close to one) the country has a rigid current account where deviations from balance are hard to sustain. In this framework, we might consider the former to be an evidence of higher degree of capital mobility as compared to the latter.

We can estimate the adjustment speed of $C A / Y$ to know whether it will return toward its equilibrium or 'steady-state' value or not. Using dynamic version of our above mentioned AR (1) model of the current account we can write down a long run or asymptotic variance of CA/Y, as it is

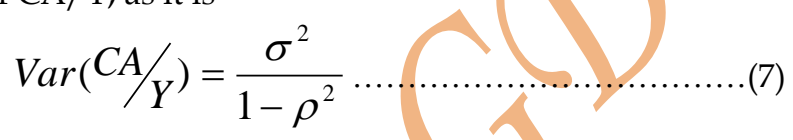

$\mathrm{Y}=\mathrm{GDP}$, Country's gross domestic product

Where $\rho=1-\beta<1$ is a persistence parameter. Hence, as it is intuitively obvious, countries will only have large current accounts surplus or deficits (according to this variance measure) only if their dynamics would allow it: if shocks are large or if the convergence speed is slow. How should we interpret the shocks $U_{i t}$ ? Using Bartlett (1948) residual periodogram, these can be construed as real shocks to the open economy resulting from a variety of sources, e.g. technology, taste, world interest rates, currency crises and so on. These will be considered the forcing terms for the equation and for the present purposes assumed to be exogenous. If the error variance $\sigma 2$ is high, it indicates a large range of real shocks to the current account; a small variance indicates more tranquil times in the external balance.

\section{Data}

The data for the empirical analysis consist of annual observations over the period of 1976 to 2012 on GDP and current account, exports of goods and services $(X)$, imports of goods and services (M), net income payments (NIP) and net current transfers (NCT). GDP and current account data, collected from World Development Indicator (WDI) of World Bank are expressed in U.S. dollar and all other variables, collected from Economic trends of Bangladesh bank are expressed in domestic currency unit, Bangladeshi taka (BDT). 


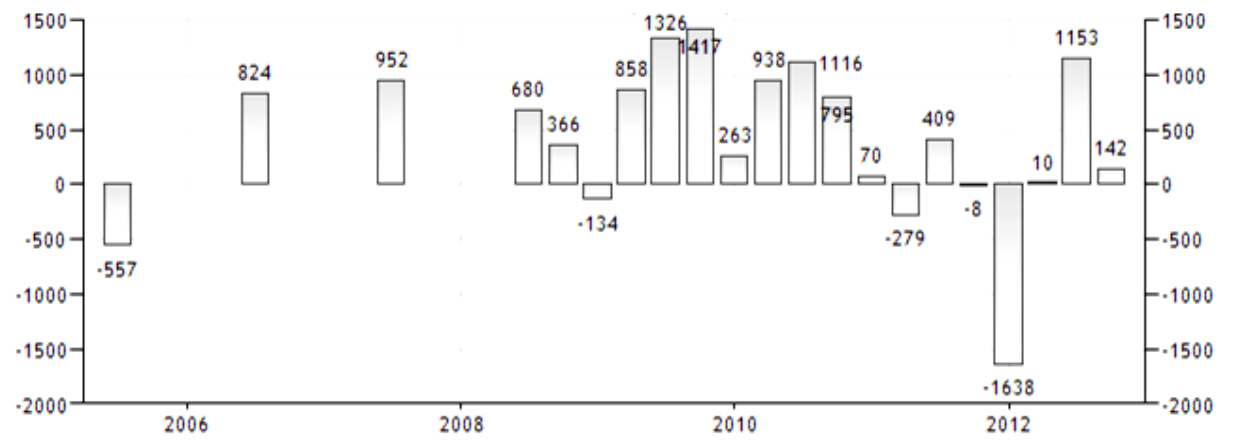

Figure I: Bangladesh Current Account (US\$) Source: World Development Indicator (2013)

Figure I show the fact of current account position in Bangladesh. As reported by Bangladesh Bank (BB), Bangladesh recorded a CA surplus of $\$ 708$ Million in the fourth quarter of 2012. Reviewing time period of 2005-2012, Bangladesh Current Account averaged \$ 427 Million reaching an all time high of \$ 1417 Million in September of 2009 and a record deficit of $\$ 1638$ Million in December of 2011.

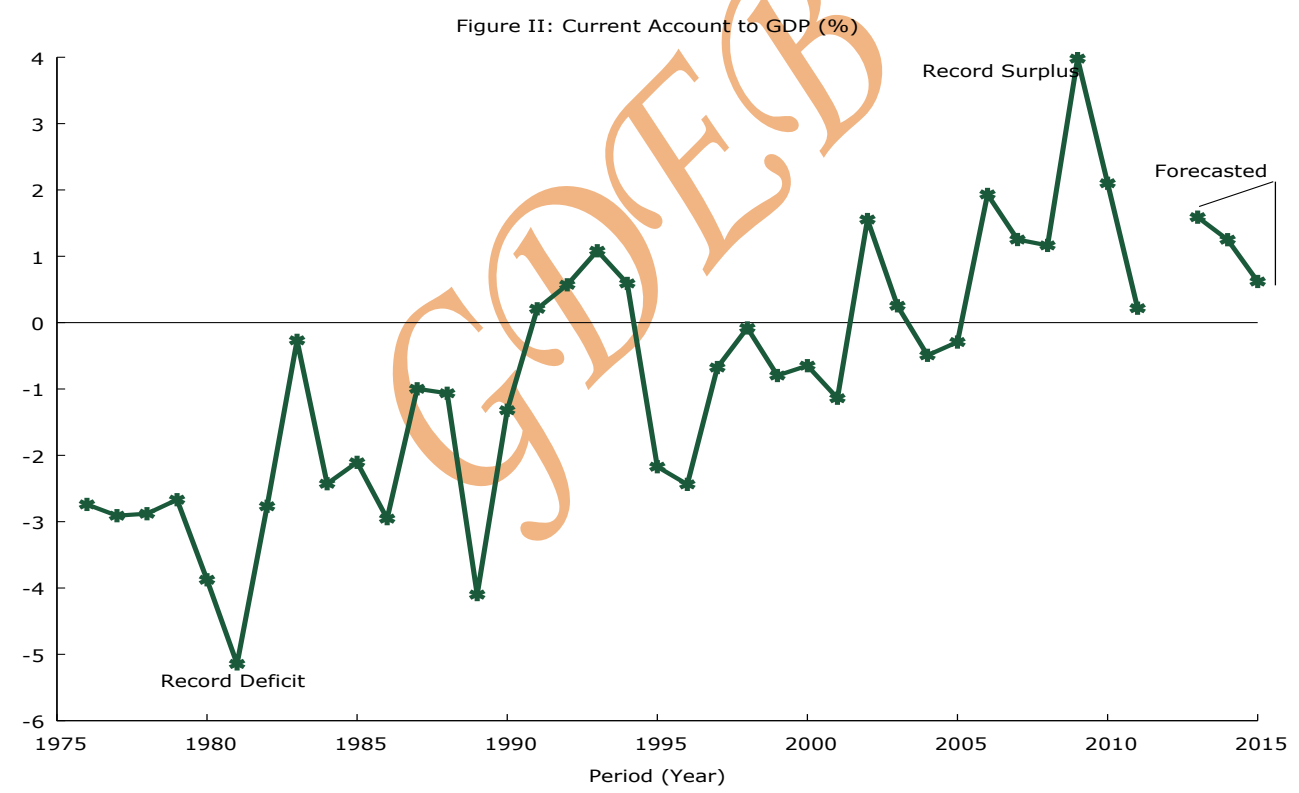

A long term deficits during the 1997-2000 periods turned into surpluses at the period of $2001-2004$ and reverted to deficits in 2004-05. Because of increasing demand of merchandise export and smooth inflow of inward remittances, CAB showed a surplus of US\$850 million during the six months of the current fiscal year 2012- 13 (July 2012-June 2013) while it recorded a surplus of $\$ 1.704$ billion in the fiscal year (FY) 2011-12. In the context of CAB as a percent of GDP which is an indication of the level of international competitiveness, figure II shows that Bangladesh recorded a CA surplus of 0.90 percent of the country's GDP in 2011. For the period of 1980 - 2011, Bangladesh CA to GDP averaged $-1.2 \%$ reaching high of $3.7 \%$ in December of 2010 and a record low of $-4.4 \%$ in December of 1988 . Despite a small CA surplus of $0.21 \%$ of GDP in 2011, Bangladesh's CA surplus is expected to be .85 and 0.62 percent of GDP in 2014 and 2015 respectively (IMF 2012). 


\section{ANALYSIS OF RESULTS}

We summarize the results of the AR (1) model in table I. As Taylor (2002) argued, these results are very remarkable in the sense that they confirm a dynamic pattern of current account adjustment and the stylized facts of macroeconomics of capital mobility.

Table I: Current account dynamics and adjustment parameter

\begin{tabular}{|l|l|l|l|l|}
\hline Periods & $\boldsymbol{\beta}$ & $\boldsymbol{\sigma}^{2}$ & $\mathbf{R}^{2}$ & $\mathbf{p}$ \\
\hline & & & & \\
\hline $1976-2003$ & $0.72(1.83)$ & 0.42 & 0.18 & 0.087 \\
\hline $2004-2012$ & $0.32(2.14)$ & 0.37 & 0.099 & $0.002^{* * *}$ \\
\hline $1976-2012$ & $0.63(2.81)$ & 0.34 & 0.45 & $0.008^{* * *}$ \\
\hline $\mathrm{F}(1,32): 22.89$ with P-value of $0.00003 \quad$; $-\mathrm{W}: 1.98$ \\
\hline
\end{tabular}

${ }_{* * *}$ Indicates that coefficient is significantly different from zero at $95 \%$ level of confidence; Significant at $5 \%$ level

First, we have examined our model for two sub-periods, for fixed exchange rate regime of 1976-2003 and for the period of flexible exchange rate regime of 2004-2012. Second, we estimated AR (1) model for overall period of 1976-2012. We considered two sub-samples with a view to compare the $C A B$ position of the two different exchange rate regimes the "Fixed Exchange Rate" and the "Free Flexible Exchange Rate" as Bangladesh Bank declared 'Free Floating Exchange Rate' of its domestic currency in 2003 (Bangladesh Bank, 2003). Looking at the results in Table I, we see that the convergence speed $(\beta)$ was quite high in the pre-2003; about $72 \%$ per annum suggests a considerable inflexibility to smooth shocks over medium to long horizons. This rigidity to adjust was reduced in the flexible exchange rate period, as the convergence speed decreased to about $32 \%$ per annum, suggesting in favor of smooth and flexible current account position. Surprisingly we see that the convergence speed $(\beta)$ is quite high for the overall period (1976-2012), about $63 \%$ per annum. For overall period, result suggests that $C A$ has remarkable inflexibility to return to its path of steady state, with a convergence speed of $63 \%$. Other parameters validate our findings as value of $\mathrm{R}^{2}(0.45)$ is quite high with $\mathrm{p}$-value of 0.008 and with the significant $t$ value of 2.81 .

We have performed Cochrane-Orcutt iterative calculation of rho and estimated the value of error variance $\left(\sigma^{2}\right)$ to be 0.34 for the overall period, and 0.37 for the flexible exchange rate time period. In both cases the error variance $\sigma 2$ is quite higher indicating lesser degree of flexibility and ability against a wide range of real shocks to the current account. Although forecasting by IMF for the period of 2013-15 is indicating a more tranquil times in the external balance, but our estimated results show dissimilarity for the value of CA to GDP. Our findings show that Bangladesh will have a rigid current account position and any deviations from balance are hard to be sustained. Therefore, forecasted values show a deficit of CA to GDP is 0.41 and 0.48 for the period of 2014 and 2015 respectively. Figure III shows dynamic forecasted value of AR (1) process for CA to GDP at $90 \%$ confidence interval. Visual inspection also reveal the dynamic forecasting error for overall time period upon which we may be skeptical on the forecasted value of CA to GDP for 2014 and 2015 time period. In order to avoid such skepticism, we have extended our investigation to an estimation of the spectrum of the residual periodogram (figure VII) using Bartlett lag window by setting manually, using the bandwidth parameter up to a maximum of half the sample size (18). We can observe a "locally" smoothed periodogram trend of current account balances as the spectrum decomposes the content of a stochastic process into different frequencies present in that process. Therefore, using spectral density estimation 
of a random signal of CA to GDP for the sequence of time periods of 1976-2012 shows that variance decreases substantially, especially in the years of flexible exchange rate period, i.e. 2005-2012 as we observe an increasing trend of current account surpluses, implying higher degrees of current account flexibility for that period.

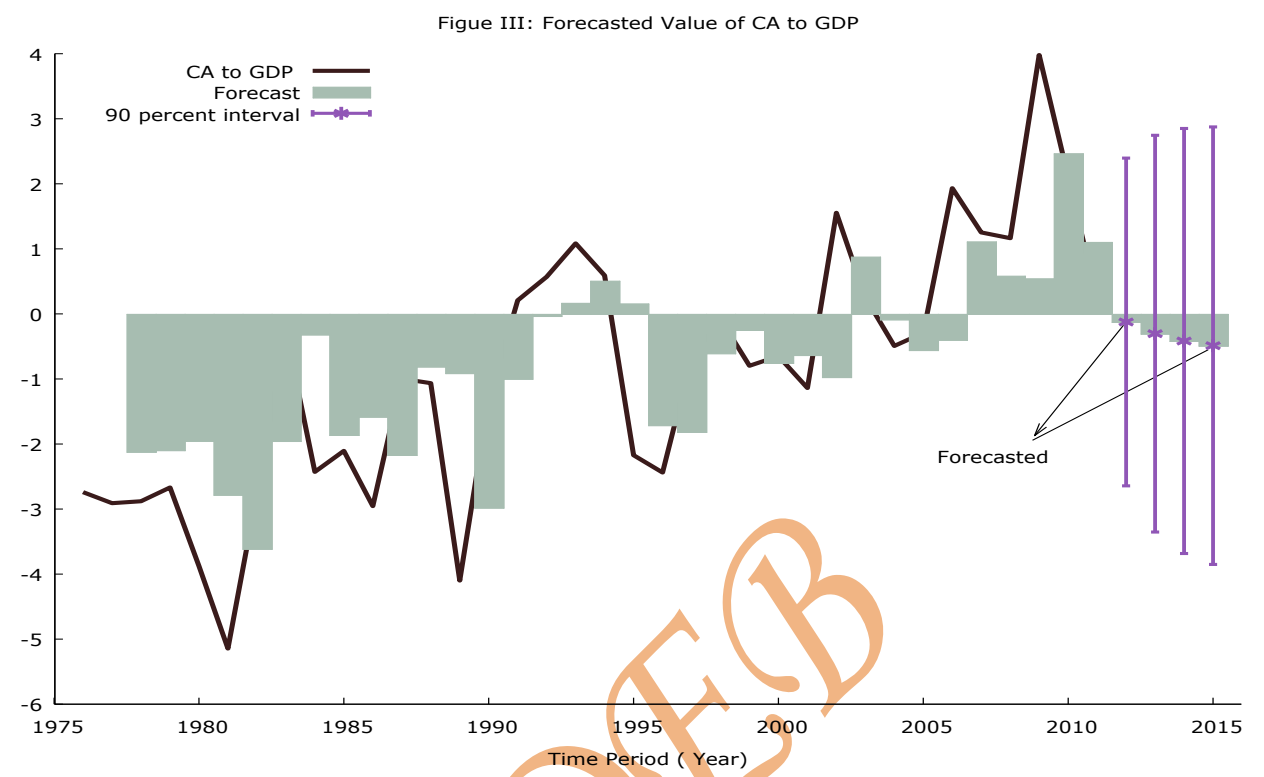

Figure III allows us to make two observations. First, the behavior of the AR (1) coefficient's standard deviations confirms the differences between actual and forecasted values for any given time period, suggesting increasing idiosyncratic shocks to CAB for the period of 2012-2015. Second, the relatively stable standard deviations in the last three decades do not suggest a smooth and persistent CA surplus for forecasted time periods. Therefore, system is not considered quite stable, or the small possibility of further back in time if a given change occurs, i.e., the less it will affect the present. But dynamic pattern of AR (1) coefficient shows the possibility to adjust the $\mathrm{CAB}$ system to more stable one as we have $|\rho|<1(0.34)$, the given change or impact of adverse shocks eventually dies down over time. Adjustment speed and implementation of dynamic system require country's prudent monetary, trade and exchange rate policy interventions. More specifically, what kind of policy interventions would lead a country to enter into a flexible system for its current account process? And how do they affect the degree of country's capital mobility and integration with the rest of the world? Future research will lead to explore these questions. Given our estimated results, a brief look at the error variance $(\sigma)$ reveals no surprises for the degree of capital mobility. Shocks were largest during the fixed exchange rate periods with higher value of $\beta$ and $\sigma 2$, indicating lower degree of capital mobility. In contrast to the flexible exchange time period (2003-2012), shock is also quite higher for overall periods, and that seems entirely consistent with the long-lasting impact of a highly controlled system designed by monetary authority of Bangladesh to both limit capital mobility and prevent shocks. The pre-flexible exchange rate periods had shocks larger than the flexible exchange rate periods, showing comparatively increased degree of country's integration with the rest of world's capital market. Furthermore, all diagnostic tests give evidence in favor of reliability of the estimated model. 
We can consider a number of possible explanations for the figures presented in appendix, displaying the series autocorrelation function, exponential moving average (EMA), cyclical components of CA to GDP series and normality distribution of residual. EMA assigns a weighting factor of 0.200 on each current observation in the data series while the most recent data get the greatest weight and used with series to smooth out short-term fluctuations and emphasize longer-term trends.

\section{Conclusions}

This paper aims to provide an examination at the pattern of dynamics of current account balances and the degree of capital mobility of Bangladesh by using simple AR(1) process. Empirical investigation mainly focuses the state of CAB position and its inflexibility against real shocks, degree of capital mobility and progress of capital market integration with rest of the World. There have been some substantive policy changes in the monetary policy and capital market in Bangladesh in recent years and, these have pointed towards the flexibility of $\mathrm{CAB}$ and increased degree of capital market integration. But the findings of AR (1) regression reveals capital immobility and indicates the rigidity of Bangladesh's current account position to smooth any external shocks over medium to long horizons. This rigidity to adjust was reduced in the flexible exchange rate period, as the convergence speed decreased to about $32 \%$ per annum, suggesting in favor of smooth and flexible current account position. But findings show a rigid current position for the overall time period. These findings are noteworthy and reveal important policy aspects of Bangladesh's external sector and the issue of capital account liberalization. The process of capital market integration actually starts with the removal of capital market imperfection, such as current and capital account liberalization, deregulation of domestic markets and removing entry barriers for foreign financial institutions. FDI and remittance become the largest sources of foreign capital flows for Bangladesh and both are continuing to exhibit an upward trend in Bangladesh. Policy implication of this paper is suggesting a comprehensive policy options in country's monetary and exchange rate policies to attract FDI, to ensure smooth flow of remittance and strengthen integration with global capital market opportunities so that country can sustain and maintain her stable and sustained current account position.

\section{RefERENCES}

[1] Bartlett, M.S. (1948). "Smoothing Periodograms from Time-Series with Continuous Spectra". Nature 161: 686-687.

[2] Brockwell, Peter J. and Richard A. Davis. (1987). Time Series: Theory and Methods. New York: Springer-Verlag.

[3] Bulut, L. (2013). Current account dynamics and degree of capital mobility. Applied Economics Letters, 20(7), 697-701.

[4] Calderon, C., Chong, A. and Loayza, N. (2002). 'Determinants of current account deficits in developing countries', Contributions to Macroeconomics, vol. 2(1).

[5] Chinn, M. and Prasad, E. (2003). 'Medium-term determinants of current accounts in industrial and developing countries: an empirical exploration', Journal of International Economics, 59(1), (January), pp. 47-76.

[6] Clower, E. and H. Ito. (2012) The Persistence of Current Account Balances and its Determinants: The Implications for Global Rebalancing. ADBI Working Paper 400. Tokyo: Asian Development Bank Institute.

[7] Faruqee, H., and J. Lee. (2009). Global dispersion of current accounts: Is the universe expanding? IMF Staff Papers 56: 574-595. 
[8] Freund, C. (2000). 'Current account adjustment in industrialized countries', International Finance Discussion Paper 692, Board of Governors of the Federal Reserve System

[9] Gunnip, Jon. (2006). Analyzing Aggregated AR (1) Processes. University of Utah.

[10] Hamilton, James D. (1994). Time Series Analysis. Princeton, NJ: Princeton University Press.

[11] Lane, P. and Milesi-Ferretti, G-M. (2004). 'International investment patterns', IMF Working, Paper 2004/134

[12] Mann, C. (1999). 'Is the US trade deficit sustainable?', Institute for International Economics, September.

[13] Obstfeld, M. and Taylor, A.M. (2005). Global capital markets: integration, crisis, and growth, Cambridge University Press, USA.

[14] Taylor, Alan M., (2002). "A Century of Current Account Dynamics," Journal of International Money and Finance, Elsevier, vol. 21(6), pages 725-748.

\section{APPENDIX}

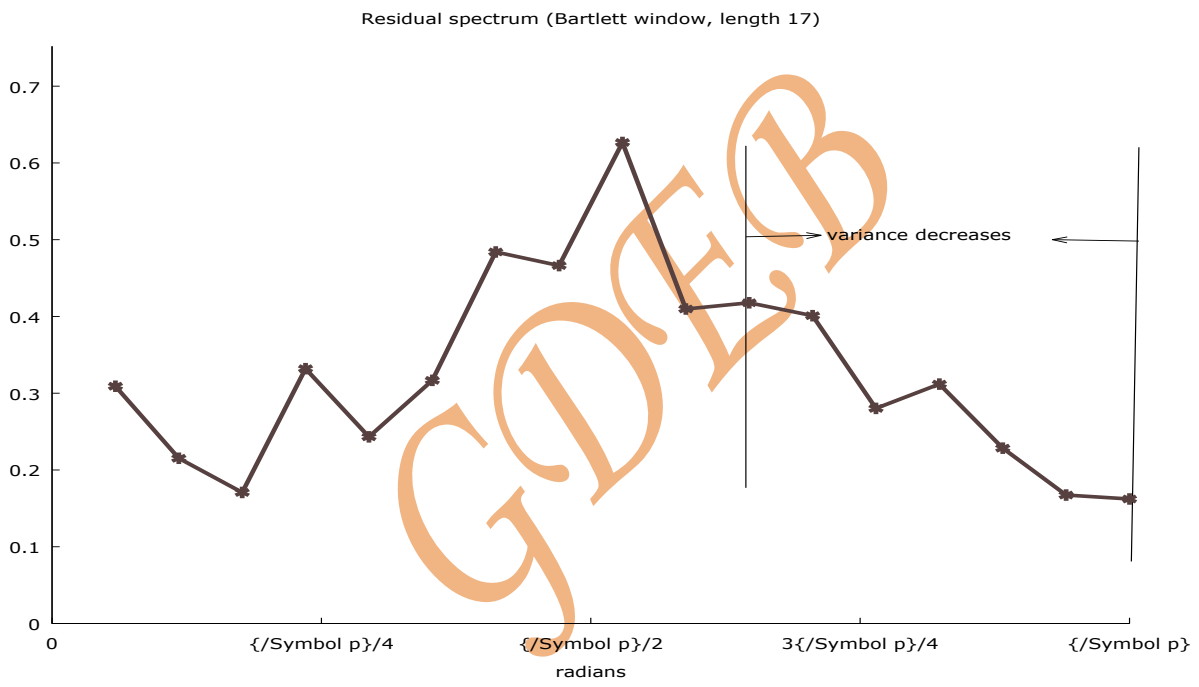

Figure IV: Residual periodogram using Bartlett lag window
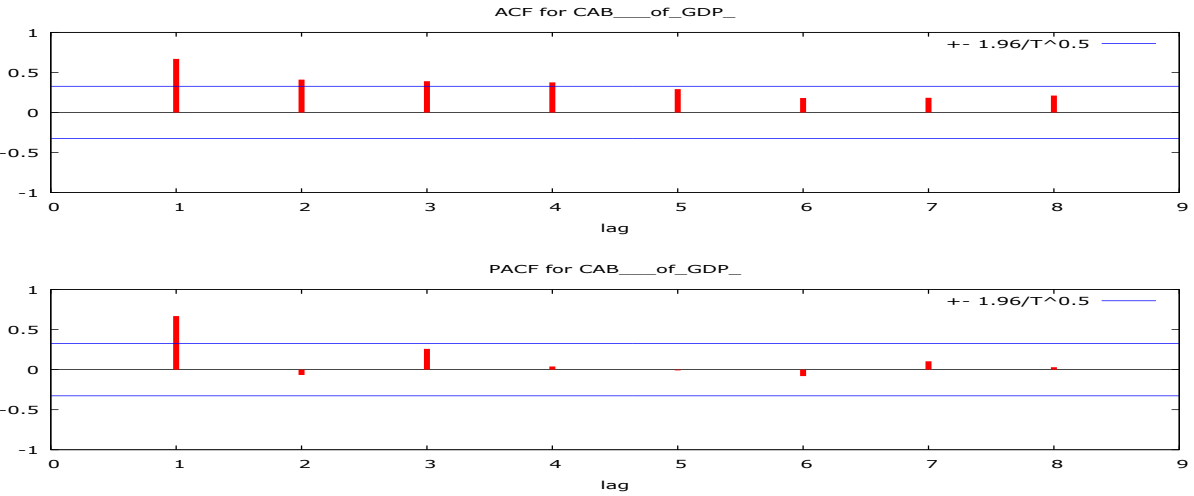

Figure V: Series autocorrelation function (lag 8) 


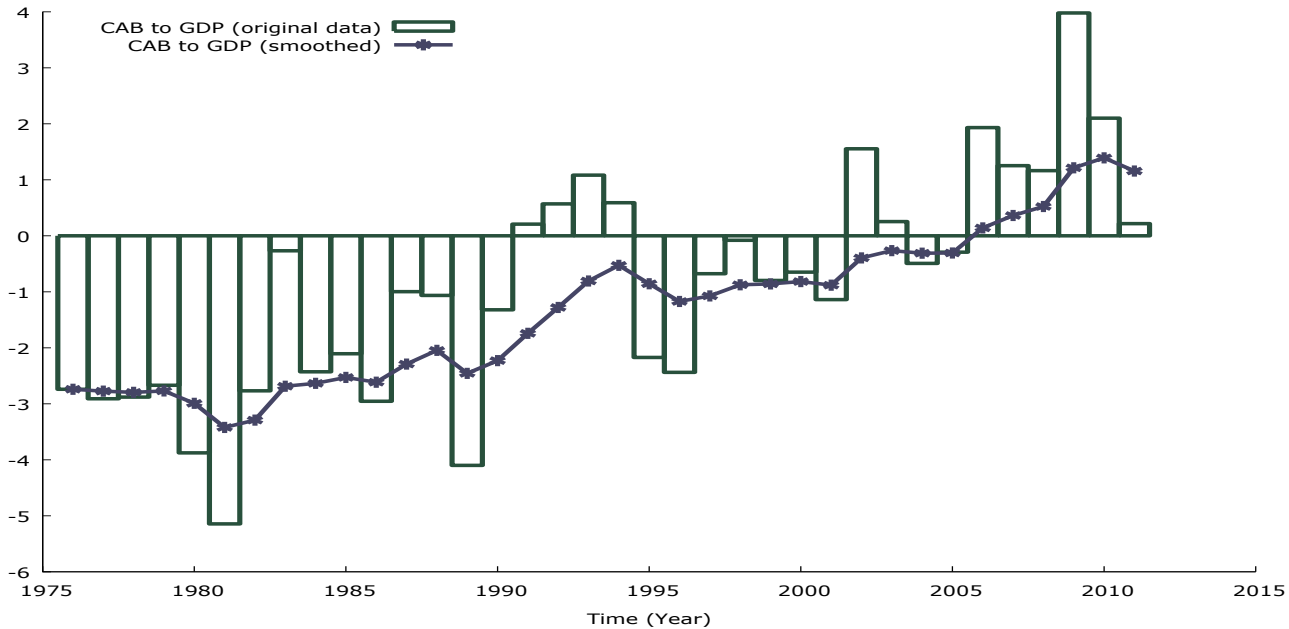

Figure VI: EMA- original and smoothed value

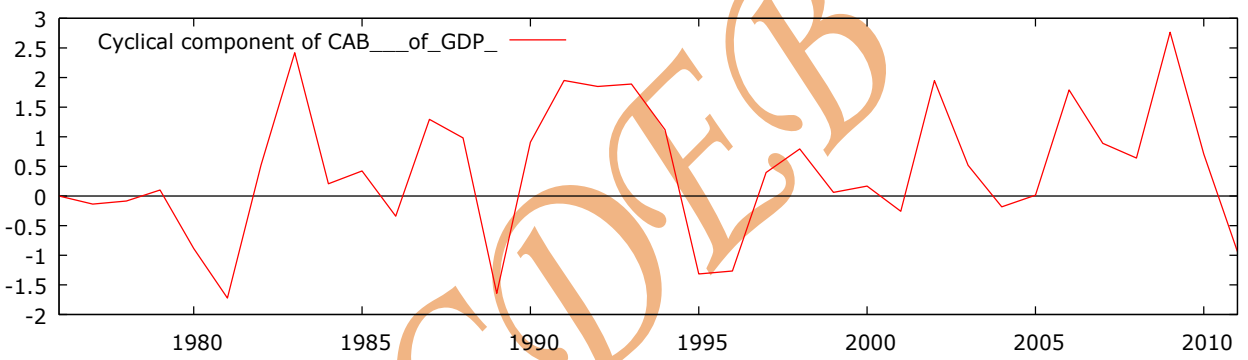

Figure VII: Cyclical components of CA to GDP (\%)

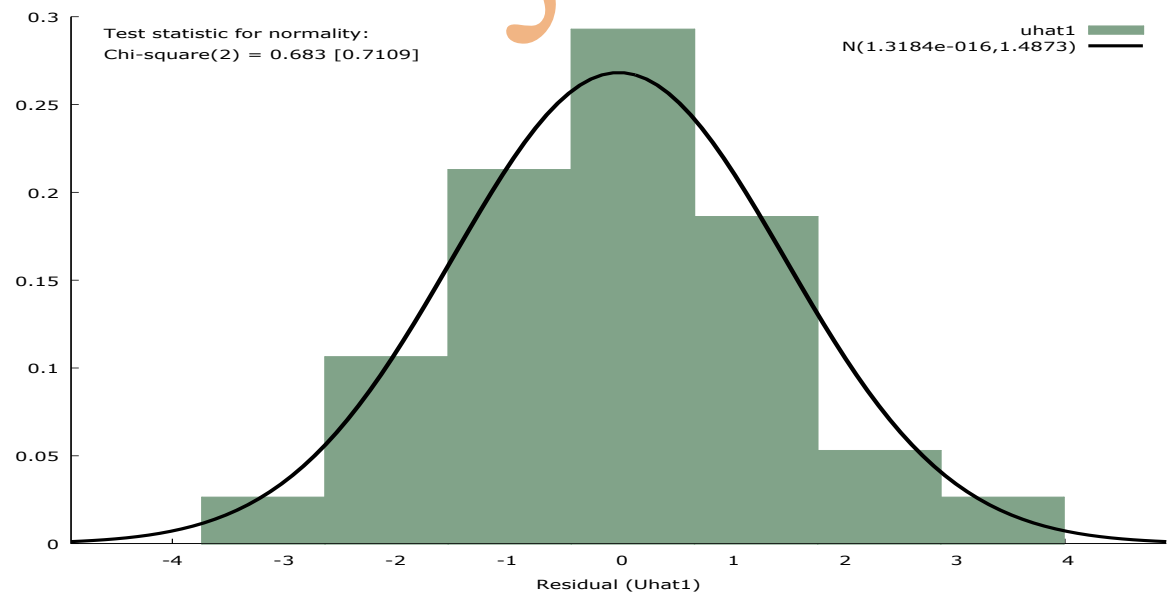

Figure VIII : Normality distribution of residual 